\title{
Uma Metodologia de Avaliação da Relação entre Perfis de Personalidade e Desempenho Acadêmico em Alunos de Sistemas de Informação
}

\author{
Alternative Title: An Evaluation Methodology of the Relation \\ Between Personality Profiles and Academic Performance in \\ Students of Information Systems
}

\author{
Giovanni Stroppa Faquin \\ IF Sudeste MG \\ Campus Juiz de Fora \\ Núcleo de Informática \\ giostroppa@gmail.com
}

\author{
Maria Luiza Furtuozo Falci \\ IF Sudeste MG \\ Campus Juiz de Fora \\ Núcleo de Informática \\ marialuiza.ff@hotmail.com
}

\author{
Marco Antônio Pereira Araújo \\ IF Sudeste MG \\ Campus Juiz de Fora \\ Núcleo de Informática \\ marco.araujo@ifsudestemg.edu.br
}

\begin{abstract}
RESUMO
O objetivo deste artigo é compreender como perfis distintos de personalidade podem ser relacionados a diferentes desempenhos acadêmicos e níveis de habilidade em disciplinas de gestão, computação e matemática em estudantes de graduação em Sistemas de Informação. Com uma abordagem metodológica interdisciplinar, a pesquisa utiliza a teoria de tipos psicológicos de C. G. Jung para avaliar como predisposições de personalidade se ligam às diversas competências requeridas de um acadêmico em Sistemas de Informação.
\end{abstract}

Palavras-Chave

Fatores Humanos; Perfis Psicológicos; Desempenho Acadêmico.

\begin{abstract}
The purpose of this article is to understand how different personality profiles can be related to different academic performances and skill levels in management, computing and mathematics disciplines in graduation students in Information Systems. With an interdisciplinary methodological approach, the research uses the theory of psychological types of C. G. Jung to evaluate how personality predispositions can be connected to the various skills required of an academic in Information Systems.
\end{abstract}

\section{Categories and Subject Descriptors}

H.1.2 [User/Machine Systems]: Human factors, Human information processing, Software psychology.

\section{General Terms}

Human Factors, Psychological Types, Academic Performance.

\section{Keywords}

Human Factors, Psychological Types, Academic Performance.

Permission to make digital or hard copies of all or part of this work for personal or classroom use is granted without fee provided that copies are not made or distributed for profit or commercial advantage and that copies bear this notice and the full citation on the first page. To copy otherwise, or republish, to post on servers or to redistribute to lists, requires prior specific permission and/or a fee.

SBSI 2016, May 17-20, 2016, Florianópolis, Santa Catarina, Brazil. Copyright SBC 2016

\section{INTRODUÇÃ̃O}

Sistemas de Informação compreendem a visão sistêmica de um conjunto de elementos computacionais e não computacionais para a solução de um problema relacionado ao fluxo de informação. Isso inclui o domínio de teorias, técnicas e ferramentas diversas, seja para a escolha de modelos de gestão ou para a produção de software de melhor qualidade. Significa ainda planejar, desenvolver e implementar produtos dentro de prazos e orçamentos estabelecidos e atender às necessidades presentes e futuras dos usuários. Em sua forma clássica e mais difundida, a construção de Sistemas de Informação se ocupa em delimitar processos e métodos de desenvolvimento de negócios e software, incluindo modelos de desenvolvimento em cascata ou ágil, engenharia de requisitos, modelagem UML, implementação e testes, entre outros temas abordados.

Paralelamente a esse tratamento sobre tais aspectos técnicos, uma outra abordagem, ainda descentralizada e menos numerosa, porém insistentemente ativa desde o surgimento dos Sistemas de Informação, busca levar em conta o papel desempenhado por fatores humanos que exerçam impacto direto sobre a qualidade no desenvolvimento de Sistemas de Informação. Neste sentido, o presente trabalho se insere em um crescente e interdisciplinar campo de estudo aberto a pesquisadores preocupados em investigar como a compreensão de dimensões cognitivas e psicológicas, de ordem pessoal ou organizacional, pode contribuir para o enriquecimento da área de Sistemas de Informação.

As habilidades requeridas de um profissional de computação são amplas variando desde competências estritamente técnicas até outras emocionais e intelectuais como a capacidade de trabalho em equipe e fluência na comunicação oral e escrita [27]. Esse conjunto plural de habilidades esperadas de um profissional em Sistemas de Informação consta em diretrizes curriculares criadas no Brasil e no exterior. É cada vez mais necessário que instituições de ensino e estudantes apliquem seus esforços não apenas com a transmissão e retenção de conteúdo disciplinar, mas que também estejam atentos a como essas habilidades são incorporadas de formas distintas pelos alunos, de acordo com seus perfis de personalidade. Empresas de tecnologia recorrem à aplicação de diversas técnicas de avaliação de personalidade em seus profissionais, seja para a contratação ou a formação de equipes. Se por um lado consolida-se uma linha de pesquisa sobre 
o estudo do papel da personalidade na atividade profissional de computação, por outro se observa a escassez de estudos focados no período de formação acadêmica do profissional em computação. Este trabalho busca dar sua contribuição à discussão sobre a formação em Sistemas de Informação.

Este trabalho é dividido em mais 6 seções além desta introdução. A seção 2 apresenta uma discussão bibliográfica a respeito da como os fatores humanos se consolidaram como uma área de pesquisa e como se deu sua posterior interseção com Sistemas de Informação. Na seção 3, é apresentada a metodologia de pesquisa baseada na descrição de tipos de personalidade segundo a teoria criada por C. J. Jung e posteriormente adaptada por Katharine e Isabel Briggs. A seção 4 mostra como se dá a aplicação da teoria jungiana no relacionamento entre um conjunto de habilidades $\mathrm{e}$ um tipo de personalidade. Na seção 5, a metodologia é aplicada para articular as habilidades trabalhadas por alunos de Sistemas de Informação aos tipos de personalidade. Por fim, a seção 6 apresenta as considerações finais e trabalhos futuros.

O objetivo deste trabalho é avançar na compreensão de como perfis distintos de personalidade podem ser relacionados a diferentes desempenhos acadêmicos e níveis de habilidade em disciplinas de gestão, computação e matemática em estudantes de graduação em Sistema de Informação de uma instituição pública da rede federal de ensino superior. Como metodologia, o presente trabalho parte da consolidação dos fatores humanos como um campo de pesquisa de apoio à atividade industrial e sua posterior interseção com a construção de Sistemas de Informação. Adicionalmente, a presente pesquisa se utiliza das contribuições da teoria de tipos psicológicos de Carl Gustav Jung [14] e da posterior apropriação realizada através do indicador de tipo de personalidade Myers-Briggs [24]. Como resultado, uma análise de diretrizes curriculares foi realizada para estabelecer pontos de contato entre as habilidades exploradas pelas disciplinas de um curso de Sistemas de Informação e os distintos perfis de personalidade dos acadêmicos.

\section{DISCUSSÃO BIBLIOGRÁFICA}

\subsection{Fatores humanos}

Pesquisas em fatores humanos tornam-se mais intensas com o término da mobilização pela $2^{\mathrm{a}}$ Grande Guerra. A atividade industrial dos países desenvolvidos voltou seus esforços para a busca por métodos de produção mais confiáveis, mensuráveis e eficientes. Para pesquisadores, havia a necessidade de transformar fenômenos físicos e tecnológicos em equivalentes comportamentais (o desempenho humano) e, em seguida, traduzir esses princípios comportamentais em uma nova tecnologia. Um grande volume de pesquisas começou a ser desenvolvido de forma pouco coordenada, ou mesmo independente, por pesquisadores de áreas tão distintas quanto medicina e engenharia metalúrgica ou aeroespacial. Esses estudos levaram à criação de uma área de conhecimento hoje preocupada em compreender o impacto do fator humano na eficiência, segurança e confiabilidade da atividade laboral [19].

O balanço da produção em fatores humanos dos últimos 60 anos atesta a ausência de unidade conceitual sobre o tema Fatores Humanos. Ideias semelhantes recebem diversos rótulos em artigos, livros e eventos: fatores humanos, erro humano, ergonomia, variabilidade humana, entre outros [23]. Uma síntese dos principais aspectos encontrados na literatura aponta três grandes gerações ou paradigmas de abordagens sobre fatores humanos:
Nos anos 50 e 60, pesquisas sobre erro humano viam a falha técnica como a principal ameaça à segurança e eficácia do trabalho: a quebra de um motor, o rompimento da fuselagem de um avião, a explosão de uma mina, por exemplo. Opondo-se à ativa tradição europeia de estudos sobre desejos reprimidos e mal adormecidos em camadas ocultas da psique humana, estudos desenvolvidos principalmente nos EUA entendiam o homem como uma extensão de sua máquina de trabalho: com economia de movimentos e funções laborais mais definidas, especializadas, rigorosas e simples obter-se-ia a máxima produtividade com o mínimo de erro [19]. Os questionamentos e as soluções colocadas por essas pesquisas eram simples, pois estímulos positivos e negativos eram entendidos dentro de uma relação de causa e consequência entendida como controlável. As principais áreas a consolidar pesquisas nessa geração foram a aviação civil e militar, transporte ferroviário e rodoviário e os setores de geração de energia elétrica, mineração de carvão e prospecção de petróleo.

Nos anos 70 e 80 os comportamentos humanos contrários às normas foram colocados como o principal causador de acidentes: falhas cognitivas decorrentes do cansaço, treinamento ineficaz, desobediência a regras, entre outros. Dessa forma, atenuar o erro humano equivaleria a aprimorar normas e processos, investir em treinamento, eliminar o comportamento de risco e potencializar a cognição através de cockpits (locais de trabalho) mais elaborados. Programas de prevenção ao cansaço e redução dos fatores físicos de stress complementavam as abordagens dessa geração. A Tabela 1 exemplifica como a teoria de fatores humanos subsidia a identificação de pontos fracos em processos e aprimoramentos em normas e treinamento baseando-se, para isto, em fatores de exposição ao erro.

Tabela 1: Comportamentos relacionados ao erro de acordo com a segunda geração de paradigma de fatores humanos [16]

\begin{tabular}{|c|}
\hline Relutância em admitir erros \\
\hline Não seguir instruções ou normas de procedimentos \\
\hline Não checar por uma segunda vez à procura de erros \\
\hline Responder irracionalmente em situações de emergência \\
\hline Realizar tarefas pensando em outras coisas \\
\hline Mau avaliador de distância, velocidade e habilidades \\
\hline $\begin{array}{c}\text { Agir de forma displicente após certo período de tempo, mesmo } \\
\text { em trabalhos arriscados }\end{array}$ \\
\hline Confundir-se com informações novas \\
\hline Ter pressa \\
\hline
\end{tabular}

De acordo com as contribuições desse paradigma, o fator humano de impacto sobre o desempenho poderia ser atenuado sob uma perspectiva motora e cognitiva através do estudo detalhado de cada um dos comportamentos descritos na Tabela 1. Com locais de trabalho mais adaptados a uma determinada função e com melhores ferramentas e treinamento obter-se-ia um incremento na eficiência e segurança de uma atividade laboral.

Dos anos 80 em diante chega-se ao moderno paradigma de entendimento do erro humano com um deslocamento de ênfase. Para que um sistema de trabalho chegue ao erro existe a contribuição de uma série de fatores situacionais, gerenciais, organizacionais, além de normas incorretamente projetadas. Tratase de uma era no qual o acidente individual é precedido por um acidente organizacional, o principal provocador do erro em si [25].

Os paradigmas de Fatores Humanos não devem ser considerados como excludentes um ao outro. Em sistemas altamente dinâmicos 
e complexos e com intensiva aplicação de trabalho intelectual, como verificado na área de Sistemas de Informação, esses paradigmas se complementam.

\subsection{Fatores Humanos e Sistemas de Informação}

Paralelamente, a computação, após os anos 60, passa a se desenvolver no sentido do uso de linguagens de programação com maior grau de abstração permitindo a construção de sistemas maiores, mais complexos e de aplicação variada [6]. Rapidamente a indústria compreendeu que abordagens mais sofisticadas e disciplinadas de engenharia deveriam ser aplicadas à nascente indústria de software.

Assim, ainda que com diferentes graus de intensidade, enfatizamse hoje paradigmas tais como: melhores normas, processos, gerenciamento e treinamentos mais rigorosos. Dentro deste paradigma, surge um imenso e diversificado conjunto de métodos que evolui nos últimos 50 anos. Frente a essa ampla gama de ferramentas, não existem técnicas e modelos universais na área [26]. A concentração de esforços aqui deve ser aplicada na adequada escolha do processo de software sob abordagem sistemática: especificação, desenvolvimento, validação e evolução com feedback permanente entre as fases. Por esse ponto de vista, uma abordagem ocorre pela via do gerenciamento técnico de software e não por questões mais "suaves" como gerenciamento de pessoas ou a administração num nível estratégico e corporativo.

Outro autor, de forma análoga, compreende que o software deve passar por processos de engenharia: é necessário disciplina, adaptabilidade e agilidade. A base é o processo: subsidiar a definição da metodologia mais adequada para a efetiva entrega de software. Esse processo de desenvolvimento de software deve ser flexível entre comunicação, planejamento, modelagem, construção e emprego. Segundo esse ponto de vista, uma variação à ênfase no processo teria sido dada pelos defensores do desenvolvimento de software ágil, que se esmeram para ressaltar a importância dos "fatores humanos" [26]. Em outra perspectiva com semelhante ênfase sobre o processo, o mesmo pode ser dividido, por exemplo, em captura de requisitos, escrita e teste dos programas, teste e entrega do sistema, manutenção do sistema, entre outros. Percebe-se, nesse cenário, a pouca literatura técnica sobre o papel humano em Sistemas de Informação e a abundância de estudos sobre técnicas e ferramentas deixando a sugestão de que os pesquisadores deveriam pular com os dois pés na pesquisa sobre Fatores Humanos. Admitir a variabilidade humana é um fator chave para determinar se metas de qualidade e prazos serão cumpridas [21].

Ainda que tenham sido compreendidos como relevantes desde o primeiro momento, o interesse por fatores humanos recebem fôlego renovado após o surgimento do manifesto ágil, em 2001 [15]. Oito dos doze princípios colocados por esse manifesto enfatizam aspectos humanos, e não tecnológicos, como essenciais para o desenvolvimento de software contemporâneo. Uma relação dos princípios de agilidade e sua inclinação a fatores técnicos ou humanos são mostradas na Tabela 2.

Uma das contribuições-chave do pensamento ágil e iterativo é a grande ênfase sobre as pessoas no desenvolvimento de software, incluindo usuários, clientes e outros stakeholders, assim como profissionais de software.

Além do manifesto ágil, tanto as recomendações curriculares da ACM/IEEE [3] quanto às diretrizes do MEC para a avaliação de formandos em Sistemas de Informação [7], ressaltam a importância do domínio de habilidades e competências não técnicas (soft-skills) conjugadas com habilidades técnicas. Como visto entre os princípios do desenvolvimento ágil, habilidades como relações interpessoais e flexibilidade desempenham um papel importante em muitas atividades da computação. Ainda que sua importância seja reconhecida, habilidades interpessoais normalmente não recebem a importância necessária em programas acadêmicos. A consideração de fatores humanos na formação acadêmica fica normalmente restrita à interação humanocomputador e administração de projetos.

Tabela 2: Princípios do software ágil [26][5]

\begin{tabular}{|c|c|}
\hline Descrição do Princípio & $\begin{array}{c}\text { Enfatiza } \\
\text { fatores } \\
\text { humanos }\end{array}$ \\
\hline $\begin{array}{c}\text { A maior prioridade é satisfazer o cliente através } \\
\text { de entregas adiantadas e contínuas de software } \\
\text { valioso }\end{array}$ & Não \\
\hline $\begin{array}{l}\text { Receber bem os pedidos de alterações, mesmo } \\
\text { atrasados no desenvolvimento, uma vez que o } \\
\text { processo ágil se utiliza das mudanças como uma } \\
\text { vantagem competitiva para o cliente }\end{array}$ & Sim \\
\hline $\begin{array}{l}\text { Entregar software frequentemente, com algumas } \\
\text { semanas a até alguns meses de intervalo, } \\
\text { preferencialmente com uma escala de tempo mais } \\
\text { curta }\end{array}$ & Não \\
\hline $\begin{array}{l}\text { O setor de negócios e os desenvolvedores devem } \\
\text { trabalhar em conjunto durante todo o projeto }\end{array}$ & Sim \\
\hline $\begin{array}{c}\text { Construir projetos ao redor de indivíduos } \\
\text { motivados, dando a eles o ambiente e o auxílio } \\
\text { que precisam e acreditar neles para ter o trabalho } \\
\text { concluído }\end{array}$ & Sim \\
\hline $\begin{array}{l}\text { O método mais eficaz e efetivo de transmitir } \\
\text { informação para e dentro de uma equipe de } \\
\text { desenvolvedores é através de uma conversa } \\
\text { presencial }\end{array}$ & Sim \\
\hline $\begin{array}{l}\text { Software que funciona é a principal medida de } \\
\text { progresso }\end{array}$ & Não \\
\hline $\begin{array}{l}\text { Processos ágeis promovem o desenvolvimento } \\
\text { sustentável, sendo que patrocinadores, } \\
\text { desenvolvedores e usuários devem estar aptos a } \\
\text { manter um ritmo constante indefinidamente de } \\
\text { produção }\end{array}$ & Sim \\
\hline $\begin{array}{l}\text { Atenção contínua ao bom desenho e à excelência } \\
\text { técnica aprimoram a agilidade }\end{array}$ & Não \\
\hline $\begin{array}{c}\text { Simplicidade - a arte de maximizar o total de } \\
\text { trabalho não feito - é essencial }\end{array}$ & Sim \\
\hline $\begin{array}{l}\text { As melhores arquiteturas, requisitos e projetos } \\
\text { emergem de equipes que se auto organizam }\end{array}$ & Sim \\
\hline $\begin{array}{l}\text { A intervalos regulares de tempo a equipe reflete } \\
\text { sobre como se tornar mais efetiva e, em seguida, } \\
\text { regula e ajusta seu comportamento de acordo }\end{array}$ & Sim \\
\hline
\end{tabular}

Atualmente, artigos científicos, eventos, livros e o feedback recebido da própria indústria de software demonstram que os fatores humanos são um consolidado e crescente campo de interesse na Tecnologia de Informação. Pesquisadores ressaltam a importância de fatores humanos, psicológicos e diversidade de habilidades [8], a qualificação e o reconhecimento de profissionais em tecnologia de informação [11], a relação entre processos cognitivos e dificuldade de aprendizagem em cursos de 
computação [20], composição de equipes [23], fatores motivacionais [10], análise de sentimentos e indicadores de sustentabilidade [1], fatores sociais e organizacionais [29], e comportamentais [15] assim como a boa comunicação, colaboração e coordenação entre equipes de desenvolvimento e stakeholders [11]. É necessário, pois, a criação de métodos de observação e avaliação do progresso dessas diversas habilidades e competências em indivíduos que ainda se encontram em seu período de formação acadêmica. A interdisciplinaridade intrínseca ao encontro entre fatores humanos e tecnologia possibilita a abertura de novas questões.

A construção de Sistemas de Informação é uma atividade eminentemente sóciotécnica. Fatores como a escolha e a coordenação de equipes, a administração de capital intelectual adquirido e acumulado em projetos e aspectos cognitivos, interpessoais e motivacionais impactam diretamente a qualidade do desenvolvimento de software. Como resposta a esses desafios, estudos têm buscado valorizar o aspecto comportamental e a personalidade como variáveis de potencial benéfico sobre o sucesso de projetos.

Este campo de pesquisa compreende que fatores humanos são uma crucial contribuição à área como complemento a pesquisas centradas em processos e tecnologias. Investigam formas de mensurar e qualificar o impacto de fatores humanos sobre a qualidade do software ao obter dados seja através de testes de personalidade, de capturas de telas [4], de participação em fóruns na Internet [28] ou de entrevistas qualitativas. Esses estudos utilizam-se de ferramentas de avaliação psicológica como as propostas por Myers-Briggs [8] e o Five-Factor Model [17].

Entre os estudos que buscam definir, através de questionários baseados nas definições do modelo Myers-Briggs sobre personalidade, traços de personalidade distintos para criar um perfil, predominam os desenvolvedores profissionais como objeto de pesquisa. A presente pesquisa compreende que uma contribuição ao tema é a investigação do papel desempenhado por fatores psicológicos em estudantes de Sistemas de Informação.

\section{METODOLOGIA}

\subsection{Tipos psicológicos e instrumento de pesquisa}

O debate a respeito dos tipos de personalidade existentes e os comportamentos relacionados se estendem desde os tempos antigos. Ao olhar para si mesmo, o homem, com sua razão, compreendeu-se como um ente dividido: corpo e alma, interioridade e exterioridade. Com a aproximação do século $\mathrm{XX}$, pesquisas sobre a mente humana receberam a inflexão de métodos científicos para lançar nova luz sobre essa cisão. A noção de equilíbrio psíquico entre consciência e inconsciência norteou as investigações que levaram ao desenvolvimento da psicanálise por Sigmund Freud [14]. Esse autor lançou as bases de uma ciência que compreendia haver no ser humano um permanente diálogo entre as camadas mais ocultas, profundas e irracionais e aquelas mais racionalizadas e definidoras de comportamentos aceitáveis dentro de um conjunto de valores sociais compartilhados em grupo. Freud, na virada para o século XX, percebeu que o diálogo entre as duas instâncias se configurava frequentemente em um confronto de impulsos e instintos ora libertos, ora reprimidos [18]. Interessou-se particularmente em investigar expressões de desequilíbrio psíquico adquiridos no curso da infância e acentuados na vida escolar, matrimonial, social ou profissional.
Interessava-o compreender, descrever e definir mecanismos mentais do indivíduo como a histeria e o recalque e sua relação com os valores defendidos por uma sociedade europeia conservadora, confrontada por profundas e irreversíveis mudanças sociais, religiosas e econômicas.

Carl Gustav Jung, discípulo de Freud, deu continuidade às observações do comportamento humano iniciadas por seu mestre. Afastou-se, entretanto, de Freud ao defender um estudo da mente humana mais voltado para a investigação do adulto, investindo em um detalhado estudo de tipos comportamentais psicológicos [14]. Jung apresenta uma diferenciação essencial entre dois tipos psicológicos ou disposições típicas da consciência: o extrovertido e o introvertido. Essas duas disposições ou atitudes se articulam com quatro funções psicológicas de orientação fundamentais: pensar e sentir (racional) e perceber e intuir (irracional). Jung cria, assim, oito combinações ou tipos psicológicos através dos quais são detalhadas características que buscam descrever, para cada indivíduo, a forma mais natural de sua disposição. Uma vez observado qual seu tipo natural, formas de descontentamento, perturbação, opressão e violência sofridas pelo indivíduo em sua singularidade psíquica tornam-se mais nítidas. Analogamente, pressões externas ou internas podem levar um indivíduo à falsificação de seu tipo, levando-o a desenvolver neuroses, só lhe sendo possível uma cura ao se restabelecer a disposição que naturalmente lhe conviria. Noções como introversão, extroversão e a ideia de compensação psíquica foram adicionadas ao vocabulário cotidiano devido à obra de Jung.

Em meio à calorosa recepção da obra de Jung no âmbito acadêmico mundial, Katharine C. Briggs e sua filha Isabel Briggs Myers estudaram a obra do psicanalista por 20 anos. Basearam-se nela para apresentar, nos anos 50, um instrumento, o questionário MBTI (Myers-Briggs Type Indicator), como forma de avaliar, no indivíduo, a tipologia criada por Jung. $O$ objetivo das pesquisadoras era organizar os tipos propostos por Jung de forma a elaborar uma forma eficaz de descrever e explicar diferenças consistentes entre personalidades e que uma avaliação desse tipo pudesse ter uma aplicação prática. Instrumentos de aferição de personalidade como o questionário MBTI são largamente aplicados na educação, desenvolvimento de carreira, comportamento organizacional, desempenho de grupo, coaching, psicoterapia com indivíduos, casais e famílias, entre outros [24].

É importante ressaltar que tanto a teoria jungiana de tipos psicológicos como a avaliação Myers-Briggs não defendem uma rotulação estática e definitiva do indivíduo. A um indivíduo é perfeitamente normal que transite por entre diferentes tipos psicológicos conforme as configurações conjunturais em que se insere. Segundo Jung, esse trânsito é um instrumento de compensação existente nos seres humanos e ocorre entre o consciente e o inconsciente. Trata-se de uma capacidade que objetiva, num indivíduo saudável, o equilíbrio psíquico. O que é colocado pela teoria é a predisposição existente em cada indivíduo à predominância de um dos tipos e sua permanência nele na maior parte do tempo. De forma semelhante, como indicado anteriormente, problemas podem surgir quando um indivíduo é levado a permanecer, de forma falseada, em uma configuração psicológica diversa à sua disposição natural ou momentânea. Segundo Jung, "o homem não é uma máquina transformável para fins totalmente diversos e que, na hipótese de ser transformada, continue funcionando com a mesma regularidade de antes. $\mathrm{O}$ homem leva sempre consigo sua história e a história da humanidade" [14]. O questionário Myers-Briggs busca, desta forma, elaborar um diagnóstico mais preciso dessas disposições e nuances no nível individual. Adicionalmente, busca contribuir 
para um atendimento mais fiel das necessidades individuais sem que isso implique em um juízo de valor entre um bom e um ruim, um superior e um inferior. A seguir são relacionadas as características das funções psicológicas aferidas [24].

\subsubsection{Funções opostas da percepção: sensação e intuição}

Sensação: utiliza as evidências fornecidas pelos cinco sentidos para perceber fatos e detalhes. Ênfase sobre o que é sabido e o que pode ser verificado. Uma pessoa mais predisposta à sensação possui uma memória mais específica, detalhada, literal e completa. Possui menos interesse sobre hipóteses, o desconhecido ou futuras possibilidades. Evita inferências e conjecturas e apoia suas decisões em fatos verificáveis.

Intuição: caracterizado pela busca por padrões, significados e possibilidades futuras que estejam implícitas no presente. Atenção a conceitos, ideias, teorias e conexões em meio a um conjunto de informações dadas. Move-se com facilidade do aqui e agora para o que pode ser possível no futuro. Dificuldade em adquirir, memorizar e aplicar dados sem colocá-los em um contexto interessante e significativo.

Para identificar a dicotomia sentir-intuir, busca-se aferir cinco pares de facetas opostas: concreto ( $\mathrm{s}$ - sentir) e abstrato (i - intuir); realístico (s) e imaginativo (i); prático (s) e conceitual (i); experiência (s) e teoria (i); tradicional (s) e original (i).

\subsubsection{Funções opostas do julgamento: pensar e sentir}

Pensar: a função do julgamento é a busca, pelo indivíduo, por uma verdade objetiva, ou pelo menos uma aproximação da verdade. Indivíduos predispostos a pensar podem julgar sobre uma distância pessoal mantendo fatores pessoais afastados de suas tomadas de decisão. $\mathrm{O}$ bem-estar e a harmonia podem apenas ser atingidos após uma conclusão pensante ter sido alcançada através de um esforço consciente. $O$ pensar não significa necessariamente uma ausência de emoção mas, antes, o esvaziamento dos valores pelo bem de uma imparcialidade e objetividade.

Sentir: geralmente aplica valores pessoais para avaliar as informações disponibilizadas pelo sentir e pelo intuir. Ao julgar pelo sentir, o indivíduo se preocupa com impactos ou consequências que essa decisão pode exercer sobre outros indivíduos ou grupos de pessoas. A decisão tomada sobre o sentir é potencializar a harmonia e o bem-estar levando em conta os sentimentos e valores do outro. Utilizam suas relações pessoais e carisma com as pessoas para atingir objetivos.

Os cinco pares de facetas da dicotomia pensar-sentir: lógica ( $\mathrm{p}$ pensar) e empatia ( $\mathrm{s}$ - sentir); cabível (p) e misericordioso (s); questionador (p) e acomodado (s); criticar (p) e concordar (s); duro (p) e delicado (s).

\subsubsection{Funções opostas da energia: extroversão e introversão}

Extroversão: atitude que direciona e recebe energia psíquica do mundo exterior de pessoas e coisas. Quando assume uma atitude extrovertida, a pessoa interage com o ambiente, recebe energia através de um ativo engajamento com pessoas e atividades e adota uma abordagem de tentativa e erro para adquirir novas experiências e habilidades. Pessoas predispostas à extroversão tendem a pensar com mais intensidade na interação e diálogo com o outro e fazem isso sem grande esforço consciente. Têm dificuldade em pensar internamente, pois se conscientizam do que estão pensando apenas quando verbalizam. Períodos longos sem atividade externa podem levar à fadiga e à baixa motivação.

Introversão: atitude que direciona a energia psíquica em direção ao mundo interior, à reflexão e às experiências internas. Em uma atitude introvertida, o indivíduo reflete e revê ideias e experiências, observa e pensa sobre se deve ou não interagir com outras pessoas ou arriscar novas atividades. Tendem a pensar internamente antes de externar seus pensamentos. Têm dificuldade em expressar seus pensamentos sem refletir sobre eles. Passar pouco tempo sozinho e muito tempo em interação com outras pessoas pode resultar em fadiga e baixa motivação.

Cinco pares de facetas da dicotomia extroversão-introversão: iniciador (e - extrovertido) e receptor ( $\mathrm{i}$ - introvertido); expressivo (e) e contido (i); gregário (e) e intimista (i); ativo (e) e reflexivo (i); entusiástico (e) e quieto (i).

\subsubsection{As duas atitudes relativas ao mundo exterior: julgar e observar}

Julgar: uma atitude de julgamento inclui a utilização das funções pensar e sentir na sua interação com o mundo externo. Ao julgar, o indivíduo deseja chegar a uma conclusão e tomar uma decisão de forma rápida e eficaz. Indivíduos que julgam tendem a ser organizados, estruturados e efetivamente trabalham dentro de prazos. Iniciam tarefas com antecedência para que prazos sejam cumpridos com folga. Evitam adiar tomadas de decisão, trabalhar sem planejamento bem como em um ambiente onde ocorrem frequentes interrupções e distrações.

Observar: envolve o uso habitual das funções sentir e intuir. Há um desejo em obter e acumular o máximo de informações antes de se chegar a uma conclusão. É flexível, adaptável e espontâneo. Lida de forma tranquila e efetiva com pressões e prazos curtos e é receptivo a interrupções e distrações, pois estimulam nova energia e proveem informações adicionais e úteis. Há dificuldade em iniciar tarefas com muita antecedência, trabalhar dentro de cronogramas estritos e a ser ordenado e metódico no atingimento de objetivos.

Os cinco pares de perfis da dicotomia julgar e perceber são: sistemática ( $\mathrm{j}$ - julgar) e casualidade ( $\mathrm{p}$ - perceber); planificador $(\mathrm{j})$ e flexível quanto aos fins (p); iniciar com antecedência (j) e estimulado por pressão (p); programado (j) e espontâneo (p); metódico (j) e emergente (p).

Da combinação das dicotomias, obtêm-se uma expressão capaz de delinear perfis de personalidade. Por exemplo, intuir-sentirextroversão-perceber é um exemplo de perfil psicológico que reúne, a cada dicotomia, uma atitude que predomina em um dado indivíduo e que indica suas predisposições mais naturais.

\section{APLICAÇÃ̃O}

Apresenta-se uma proposta de aplicação da metodologia de tipos de personalidade em um universo de ensino de graduação em Sistemas de Informação. Os tipos de personalidade identificados e as características mais naturais a cada indivíduo são aplicados sobre um quadro de habilidades desenvolvidas pelos alunos ao longo do curso conforme apresentado na Tabela 3. Esse primeiro movimento permite visualizar como diferentes tipos de personalidade podem ser ligados a diferentes habilidades.

Em sua aplicação, Capretz e Ahmed [8], que utilizaram a metodologia MBTI, afirma que o desempenho de profissionais de tecnologia da informação pode ser influenciado pelos fatores humanos, favorecendo um bom desempenho caso as habilidades inerentes do tipo de personalidade sejam compatíveis com as 
desejadas pelo papel desenvolvido. Entretanto, uma personalidade favorável a um cargo não determina um bom desempenho, já que muitos outros fatores humanos podem exercer influência sobre o desempenho dos profissionais, como fatores organizacionais e de grupo, além de motivação, experiência, alegria, estima, controle como informado na Tabela 4.

Tabela 3: Relação entre personalidade e habilidades e competências desejadas em um profissional (adaptado de [8])

\begin{tabular}{|c|c|}
\hline $\begin{array}{c}\text { Requisitos em habilidades } \\
\text { emocionais } \\
\text { (soft skills) }\end{array}$ & \\
\hline Habilidades de comunicação & \multirow{2}{*}{$\begin{array}{c}\text { Tipos de } \\
\text { personalidade }\end{array}$} \\
\hline Habilidades interpessoais & \\
\hline Habilidade em trabalhar & Extroversão \\
\hline independentemente & Introversão \\
\hline Escuta com atenção & Sensação \\
\hline $\begin{array}{l}\text { Sólidas habilidades analíticas e } \\
\text { em solução de problemas }\end{array}$ & Intuicão \\
\hline Aberto e adaptado a mudanças & \\
\hline Inovador & Julgar \\
\hline $\begin{array}{l}\text { Habilidades organizacionais } \\
\text { Grande atenção a detalhes }\end{array}$ & $\frac{\text { Julgar }}{\text { Observar }}$ \\
\hline Aprendizado rápido & \\
\hline Trabalha bem em equipe & \\
\hline
\end{tabular}

Tabela 4: Fatores humanos de influência sobre o desempenho nos níveis individual, grupo e organização

\begin{tabular}{|c|c|}
\hline Níveis & Fatores humanos \\
\hline Individual & Locus de controle \\
\cline { 2 - 2 } & Autoeficiência \\
\cline { 2 - 2 } & Autoestima \\
\cline { 2 - 2 } & Autodisciplina \\
\hline \multirow{2}{*}{ Grupo } & Pensamento de grupo \\
\cline { 2 - 2 } & Composição do time \\
\hline Organização & Mudança organizacional \\
\cline { 2 - 2 } & Cultura organizacional \\
\hline
\end{tabular}

Vários fatores humanos influenciam diferentes áreas da tecnologia da informação. Segundo Lenberg [15] existem três grupos de influência, são eles o individual, o grupo e a instituição. Dentro de cada grupo, existem fatores específicos de influência. Para a organização, a mudança organizacional e a cultura organizacional são os mais influentes. Para o grupo, o pensamento do grupo e a composição do time de trabalho são os mais relevantes. Já para o individual, a auto estima, a auto disciplina, auto eficiência e o locus de controle são os destacados pelo autor. Dentre esses três grupos, o foco do presente trabalho está no individual, no caso especificamente o aluno. Os fatores humanos cuja influência será estudada, no entanto, serão a personalidade e as habilidades e competências.

Apesar de ser a personalidade de grande relevância na hora da escolha de um profissional para um cargo, não é indicado que apenas a personalidade seja levada em consideração, nem tampouco que apenas profissionais com um mesmo perfil de personalidade sejam escalados para realizar alguma atividade de tecnologia da informação. A diversidade de personalidades também pode ser um ponto positivo, e muitas vezes necessário. Mesmo assim, segundo Capretz, autor que fala sobre a influência da personalidade em tecnologia da informação, a escolha dos profissionais com características específicas de personalidade para determinados cargos pode determinar o sucesso de um projeto [8].

Desta forma, para efeitos deste trabalho, busca-se uma forma de identificar os tipos de personalidade em indivíduos que se encontram em sua formação acadêmica. Para isso, procede-se a uma análise dos componentes curriculares acadêmicos. $\mathrm{O}$ objetivo é encontrar pontos de encontro entre os tipos de personalidade colocados pela teoria junguiana e a metodologia Myers-Briggs e as habilidades esperadas de alunos de um curso de Sistemas de Informação. Utilizou-se como referência a matriz curricular do Projeto do Curso de Bacharelado em Sistemas de Informação de uma instituição da rede federal de ensino superior [13]. Essa matriz conta com 3 grandes grupos, cada um com linhas de disciplinas afins como mostrado na Tabela 5.

\section{Tabela 5: Mariz curricular do curso de Sistemas de Informação [13]}

\begin{tabular}{|l|l|}
\hline Núcleo & Disciplina \\
\hline Formação Geral & $\begin{array}{l}\text { Matemática } \\
\text { Matemática Computacional } \\
\text { Comunicação e Expressão } \\
\text { Metodologia Científica }\end{array}$ \\
\hline \multirow{2}{*}{$\begin{array}{l}\text { Formação } \\
\text { Tecnológica }\end{array}$} & $\begin{array}{l}\text { Sistemas Operacionais e Redes } \\
\text { Programação } \\
\text { Modelagem de Sistemas } \\
\text { Tópicos Especiais }\end{array}$ \\
\hline $\begin{array}{l}\text { Formação } \\
\text { Humanística }\end{array}$ & $\begin{array}{l}\text { Computação e Sociedade } \\
\text { Administração Organizacional e Direito } \\
\text { Trabalho de Conclusão de Curso }\end{array}$ \\
\hline
\end{tabular}

Percebe-se que o curso de Sistemas de Informação envolve o desenvolvimento de um variado leque de competências: tecnológicas, abstratas, humanísticas, organizacionais, individuais e interpessoais. Essa pluralidade de competências é apresentada em diversos documentos como diretrizes curriculares da Association for Information Systems e a Association for Computing Machinery e do Ministério da Educação e Cultura [7]. Profissionais em Sistemas de Informação devem possuir conhecimentos sobre computadores, comunicação e software. Adicionalmente, ao operarem dentro de organizações, eles devem possuir habilidades relativas a administração, contabilidade, finanças, marketing, operações, recursos humanos entre outros. Além de habilidades técnicas e organizacionais, a formação em Sistemas de Informação deve incluir o desenvolvimento de pensamento sistêmico, análise de problemas de negócios, habilidades de comunicação oral e escrita e trabalho em equipe tanto pessoal como virtualmente [27].

\section{RESULTADOS: PERSONALIDADE, HABILIDADES E CURRÍCULO}

A seguir é apresentado o cruzamento entre 1) habilidades desejadas em profissionais de Sistemas de Informação, 2) as disciplinas do curso de Sistemas de Informação que exploram essas habilidades, e 3) as características mais afeitas aos tipos psicológicos anteriormente descritos. Parte-se da descrição de uma competência e suas habilidades correlatas. Em seguida, são selecionados os núcleos disciplinares que possuem correspondência com as habilidades colocadas. Por fim, dentre os tipos psicológicos enumerados e as características das habilidades 
detalhadas, um tipo de personalidade é traçado. As habilidades aqui analisadas buscam englobar aquelas descritas como necessárias nas diretrizes curriculares da ACM/IEEE, MEC e instituição pesquisada, e também aquelas destacadas pelo princípio do software ágil.

Liderança e trabalho em equipe: estudantes devem desempenhar tarefas que envolvam trabalho coletivo. Ênfase sobre a importância da disciplina, pontualidade, comunicação e avaliação de desempenho individual e em equipe. São habilidades exploradas, em maior grau, nas disciplinas do núcleo de formação humanística: Computação e Sociedade, Administração Organizacional e Direito. Perfis de intuição (percepção), pensar (julgamento), extroversão (energia) e julgar (mundo exterior) são mais predispostos à abstração necessária ao aprendizado e sistematização de um novo conteúdo em uma forma coerente, bem como à organização de trabalho em grupo e liderança.

Preocupação com o usuário final: demonstrar entendimento e valorização quanto à importância da negociação, dos hábitos efetivos de trabalho, da liderança e boa comunicação com stakeholders em um típico ambiente de desenvolvimento de software. São habilidades exploradas nas disciplinas do núcleo de formação tecnológica e humanística: Sistemas Operacionais e Redes, Programação, Modelagem de Sistemas, além de disciplinas com ênfase em ética, impactos sociais e gestão. Perfis predispostos à sensação (percepção), sentir (julgamento), extroversão (energia) e observação (mundo exterior) são mais adaptados às exigências de flexibilidade, adaptação e espontaneidade na relação com usuários finais e clientes.

Realizar conciliações: solucionar conflitos quanto aos objetivos de um projeto, encontrar compromissos aceitáveis dentro dos limites de custo, tempo, conhecimento, sistemas existentes e das organizações. São habilidades exploradas nas disciplinas do núcleo de formação tecnológica e humanística, principalmente em atividades que dialoguem com outras disciplinas e que possuam maior dimensão e complexidade como trabalhos de conclusão de curso. Perfis predispostos à intuição (percepção), sentir (julgar), extroversão (energia) e julgar (mundo exterior) possuem mais naturalidade com essa habilidade.

Contínuo desenvolvimento pessoal: aprender novos modelos, técnicas e tecnologias na medida em que surgem e valorizar a necessidade de contínuo desenvolvimento profissional. Compreender claramente que processos, qualidade e segurança são importantes objetos para o contínuo estudo. Trata-se de habilidades perceptíveis em graduandos que buscam conhecimento alternativo em disciplinas optativas, tópicos especiais e atividades extracurriculares: línguas estrangeiras, projetos de pesquisa, laboratórios, atividades recreativas e voluntariado. Perfis predispostos à intuição (percepção), sentir (julgamento), introspecção (energia) e observar (mundo exterior) tendem a explorar de forma natural a descoberta de novos saberes.

Exercitar julgamento crítico: avaliar possibilidades de solução é uma parte chave da construção de sistemas de informação. Estudantes devem ser levados a construir o conhecimento, a habilidade de análise e os métodos que o auxiliarão em decisões importantes. Especialmente importante é a capacidade de pensar criticamente. Estudantes devem ser ensinados a julgar a confiabilidade de várias fontes de informação. São habilidades desenvolvidas em disciplinas do núcleo de formação geral (matemáticas e metodologia científica) e formação tecnológica (programação e modelagem de sistemas) pelo grau de autonomia e controle exigido dos alunos. Perfis abertos à sensação (percepção), pensar (julgamento) introspecção (energia) e julgar (mundo exterior) são mais adaptados ao grau de detalhamento, sistematização e objetividade exigidos nas áreas aqui citadas.

É importante ressaltar que a função do tipo psicológico não é criar um rótulo e fixar uma pessoa a determinada característica. Analogamente, afirma-se que indivíduos não devem ser compreendidos como componentes modulares indistinguíveis um do outro. Como visto anteriormente, a formação em Sistemas de Informação deve desenvolver e enfatizar o domínio de habilidades técnicas, intelectuais, emocionais e interpessoais. Essa variedade de competências poderá ser mais bem contemplada se o autoconhecimento for uma habilidade desenvolvida nos profissionais desde seu período de formação acadêmica através da utilização, dentro do escopo deste trabalho, da metodologia de tipos de personalidade e a compreensão de suas flutuações. Seja no ambiente acadêmico ou no profissional, a diversidade é um princípio crescentemente defendido e valorizado. A função da predisposição é proporcionar ao aluno uma forma complementar de autoconhecimento e ao docente uma oportunidade de compreender como uma mesma habilidade é incorporada de forma distinta por diferentes indivíduos. Dessa forma, tipos psicológicos diversos podem resultar em abordagens diferentes às habilidades trabalhadas em sala de aula.

\section{CONSIDERAÇÕS FINAIS E TRABALHOS FUTUROS}

Considerando-se que fatores humanos podem influenciar o desempenho de profissionais no mercado, por analogia, considerase que esses fatores exerçam influência proporcional no desempenho de atividades acadêmicas em alunos de Sistemas de Informação. Assim como um cargo exige determinadas habilidades e competências dos profissionais, disciplinas também exigem dos alunos em seus ambientes acadêmicos. Como trabalho futuro, será realizado um estudo experimental com alunos do curso de Bacharelado em Sistemas de Informação do Instituto Federal do Sudeste de Minas Gerais - Campus Juiz de Fora. O curso iniciou suas atividades em 2011, e as entradas são anuais com turmas de 36 alunos. No estudo serão distribuídos questionários aos alunos com matrículas ativas, devidamente preparados para avaliar os objetivos desse estudo. $\mathrm{O}$ objeto de avaliação é a relação entre as habilidades e competências dos alunos e seu desempenho acadêmico. Assim, serão aplicados questionários que mapeiam as habilidades e características pessoais de cada aluno, baseados tanto na teoria de tipos de personalidade de Jung quanto no MBTI. Após a coleta, os dados serão analisados utilizando métodos estatísticos apropriados e técnicas de avaliação de hipóteses, relacionando os dados qualitativos dos questionários e os dados quantitativos de desempenho acadêmico [30].

\section{AGRADECIMENTOS}

Os autores agradecem ao IF Sudeste MG, à FAPEMIG e ao CNPq pelo apoio financeiro a este projeto.

\section{REFERÊNCIAS}

[1] Aires, N. B., Sales, P., Lopes, L. V., van Vessen Jr, M., Machado, E. F., \& da Silva, C. F. (2015). Proposta do Uso de Análise de Sentimento no Desenvolvimento de uma nova Métrica de Sustentabilidade. In: Simpósio Brasileiro de Sistemas de Informação. SBC. p. 455-458.

[2] Ardini, Amalia et al. 2014. Social computing for software engineering: A mapping study. In: Computer Science Review, v. 13, p. 75-93. 
[3] Ardis, Mark et al. 2015. SE 2014: Curriculum Guidelines for Undergraduate Degree Programs in Software Engineering. Computer, v. 48, n. 11, p. 106-109.

[4] Bao, Lingfeng et al. 2015. Reverse engineering time-series interaction data from screen-captured videos. In: Software Analysis, Evolution and Reengineering (SANER), 2015 IEEE 22nd International Conference on. IEEE. p. 399-408.

[5] Beck, Kent et al. 2001. The agile manifesto. Disponível em: www.agilemanifesto.org. Acesso em: fev/2016.

[6] Boehm, B. 2006. A view of 20th and 21st century software engineering. In Proceedings of the 28th international conference on Software engineering (pp. 12-29). ACM.

[7] Brasil. 2014. Portaria Inep n. 265, de 02 de junho de 2014.

[8] Capretz, Luiz F., \& Ahmed, F. 2010. Making sense of software development and personality types. In IT professional, 12(1), 6-13.

[9] Dhillon, Balbir S. 2007. Human reliability and error in transportation systems. Springer Science \& Business Media.

[10] França, César; Sharp, Helen; Da Silva, Fabio Q. B. 2014. Motivated software engineers are engaged and focused, while satisfied ones are happy. In: Proceedings of the 8th ACM/IEEE International Symposium on Empirical Software Engineering and Measurement. ACM. p. 32.

[11] de Freitas Rocha, E. C. 2015. Qualificação e reconhecimento de profissionais de Sistemas de Informação. In: Simpósio Brasileiro de Sistemas de Informação. SBC. p. 603-610.

[12] Furnham, Adrian. 1996. The big five versus the big four: the relationship between the Myers-Briggs Type Indicator (MBTI) and NEO-PI five factor model of personality. In Personality and Individual Differences, v. 21, n. 2, p. 303307. DOI= http://doi:10.1016/0191-8869(96)00033-5

[13] IF Sudeste MG. 2014. Matriz curricular do curso de Sistemas de Informação.

[14] Jung, C. G. 1976. Tipos Psicológicos. Rio de Janeiro: Zahar.

[15] Lenberg, Per; Feldt, Robert; Wallgren, Lars-Göran. 2014. Towards a behavioral software engineering. In Proceedings of the 7th International Workshop on Cooperative and Human Aspects of Software Engineering. ACM. p. 48-55.

[16] Licorish, Sherlock A.; Macdonell, Stephen G. 2015. Communication and personality profiles of global software developers. Information and Software Technology, v. 64, p. 113-131.

[17] Licorish, Sherlock; Philpott, Anne; Macdonell, Stephen G. 2009. Supporting agile team composition: A prototype tool for identifying personality (in) compatibilities. In: Proceedings of the 2009 ICSE Workshop on Cooperative and Human Aspects on Software Engineering. IEEE Computer Society. p. 66-73.

[18] Marcuse, H. 1968. Eros e civilização. Zahar, Rio de Janeiro.

[19] Meister, D. 1999. The history of human factors and ergonomics. Lawrence Erlbaum Associates.

[20] Pessoni, V. V., Federson, F. M., \& Vincenzi, A. M. R. 2015. Learning Difficulties in Computing Courses: Cognitive Processes Assessment Methods Research and Application. In In: Simpósio Brasileiro de Sistemas de Informação. SBC. p. 31-38.
[21] Pfleeger, Shari Lawrence. 2004. Engenharia de software: teoria e prática. São Paulo: Prentice Hall.

[22] Pressman, Roger S. 2011. Engenharia de software: uma abordagem profissional. $7^{\text {a }}$ Edição. Ed: McGraw Hill.

[23] Proctor, Robert W.; Van Zandt, Trisha. 2008. Human factors in simple and complex systems. CRC press.

[24] Quenk, Naomi L. 2009. Essentials of Myers-Briggs type indicator assessment. John Wiley \& Sons.

[25] Reason, James. 1990. Human error. Cambridge university press.

[26] Sommerville, Ian. 2003. Engenharia de software. Addison Wesley, São Paulo.

[27] Topi, H., Valacich, J. S., Wright, R. T., Kaiser, K. M., Nunamaker Jr, J. F., Sipior, J. C., \& De Vreede, G. J. 2010. Curriculum guidelines for undergraduate degree programs in information systems. ACM/AIS task force.

[28] Vasilescu, Bogdan. 2014. Human aspects, gamification, and social media in collaborative software engineering. In Companion Proceedings of the 36th International Conference on Software Engineering. ACM. p. 646-649.

[29] Vyas, Dhaval. 2013. Ethnography of software maintenance activities in an industrial engineering setup. In: Proceedings of the 11th Asia Pacific Conference on Computer Human Interaction. ACM. p. 242-246.

[30] Wohlin, C., Runeson, P., Höst, M., Ohlsson, M. C., Regnell, B., \& Wesslén, A. 2012. Experimentation in software engineering. Springer Science \& Business Media. 